\title{
Ecosystems and Green Connections: Representation and Strategy for Cremona Landscape
}

\author{
Alessandro Bianchi
}

\section{Abstract}

The research work, object of this paper, is included in the Fragile Territories project of the Department of Architecture and Urban Studies of the Politecnico di Milano.

The province of Cremona where the research is handled is traditionally where rural areas confront expanding urbanization located in northern Italy. With the help of the GIS software, Cremona's current status was analyzed in terms of different qualities. The results revealed some issues that should be considered when representing and developing the landscape strategy, like quality of the green, water pollution, soil contamination, etc. Correlatively with these results, the proposed research and project development is aimed to represent the symbiotic relationship between the phenomenon of how different types of greens that serve different social and environmental functions work and harmonize with each other, connecting and enhancing landscapes that have been fragmented trough the wild urbanization happened after the second world war time. At the same time, this paper aims to demonstrate how the representation of new mobility connections might become a sort of fil rouge with the history of a place. In fact we need to rediscover the precious signs on the territory, existing before the wild industrialization and urbanization destroyed them after second world war, to go ahead with our designing proposals; this is the reason because landscape representation is a fundamental topic of our contemporaneity.

Keywords

landscape, representation, mobility, connection, Cremona.

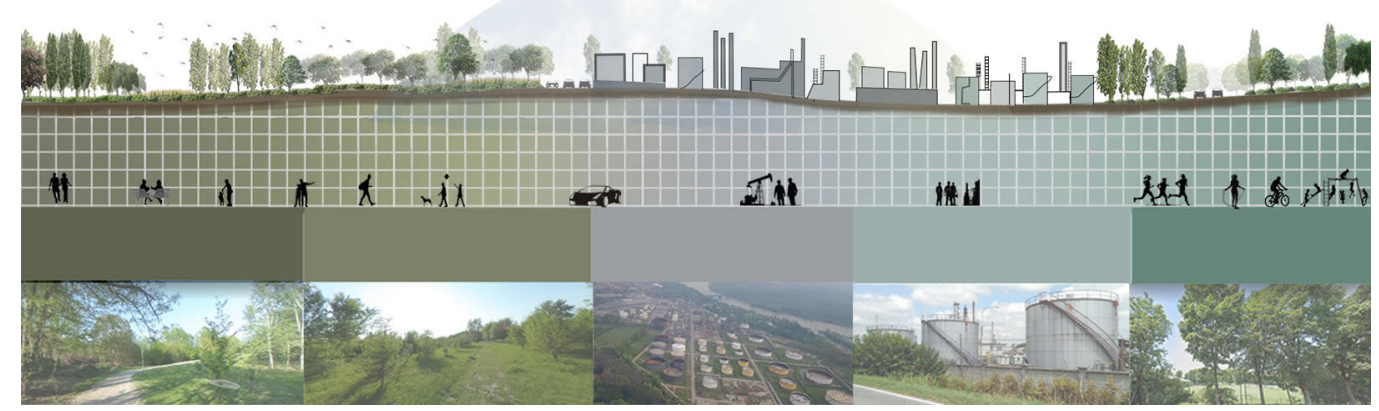




\section{Introduction}

Current perception and the appearance of the landscape are subjected to changes that are increasing, due to the quantity and quality of the human intervention on the landscape [Sereni |96|].

Nevertheless, even if the environment influenced the development of human civilization in some territories, it has been the man who shaped and modified the environments, changing them in a significative way. These altering interventions remain still visible even when the human acts (operations) cease to exist, giving life to hybrid landscapes that, while showing signs of anthropization, do not lack a 'human' component.

The territory of the Municipality of Cremona is part of a very important ecological system rich in biodiversity that make the landscape of these places special. Their representation becomes so interesting in the light of contemporary needs, including problems related to the reuse of abandoned resources with an eye to the history of the agricultural landscape. The paper aims to recover the interest lost for the marginal rural areas in decline and semi-abandoned areas, intervening both on the landscape representation and on the perception of itself by the inhabitants and tourists [Clément 2004].

The ultimate goal is to make the area under examination a place where both activities related to slow lifestyle and activities of crucial importance can be concentrated and to preserve and encourage the cultivation of the typical species of the area; a place where visitors can become both users of the landscape and observers of a process aimed at sustainable lifestyle. It is very important the representation because by the representation of old imagines and maps we can understand a possible direction for the future [Sereni I96 I].
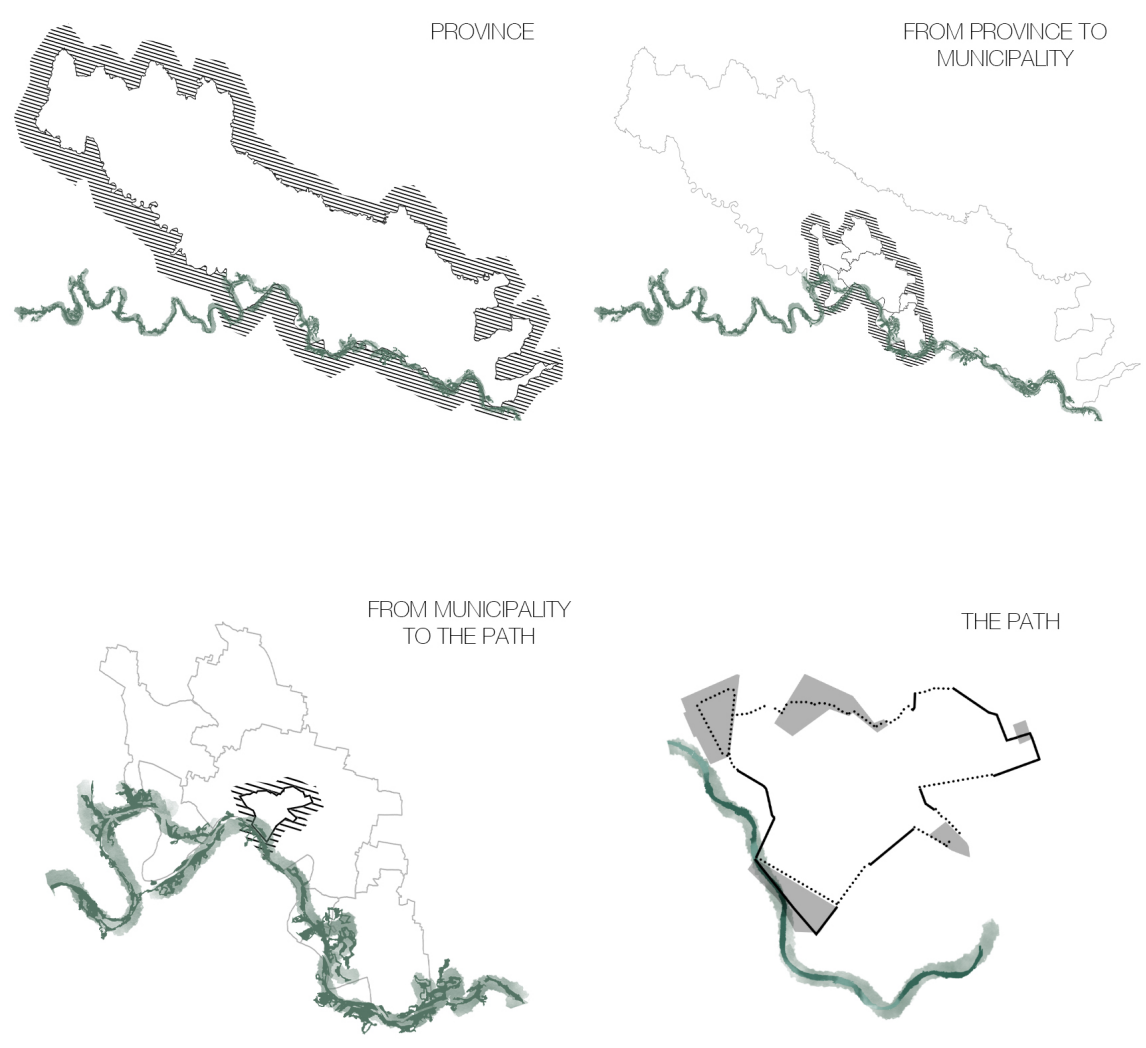


\section{Territorial representation and QGIS analysis}

In order to understand the qualities of the landscape character, QGIS data representation technique [Congedo 202I], is used in the scale of territory as a starting point [Liu, Nijhuis 2020]. Within the analysis, the land cover is defined with the headlines of terrestrial and wetland ecosystems [Lee, Hwang et al. 2009]. With the definition of these maps, the question of how these areas are covering the land occurred. The answer was found by analyzing natural greens, semi natural areas, urban coverage and how they were distributed.

When the main analysis of ecosystems was done over the maps in the scales of the territory and municipality as shown in QGIS data (fig. 2), the question of where the highest existing connections of two elements of landscape, which are the Cremona city and Po river has been solved. The main and most important relationship exists in correspondence with the least distance between Cremona city and Po river.
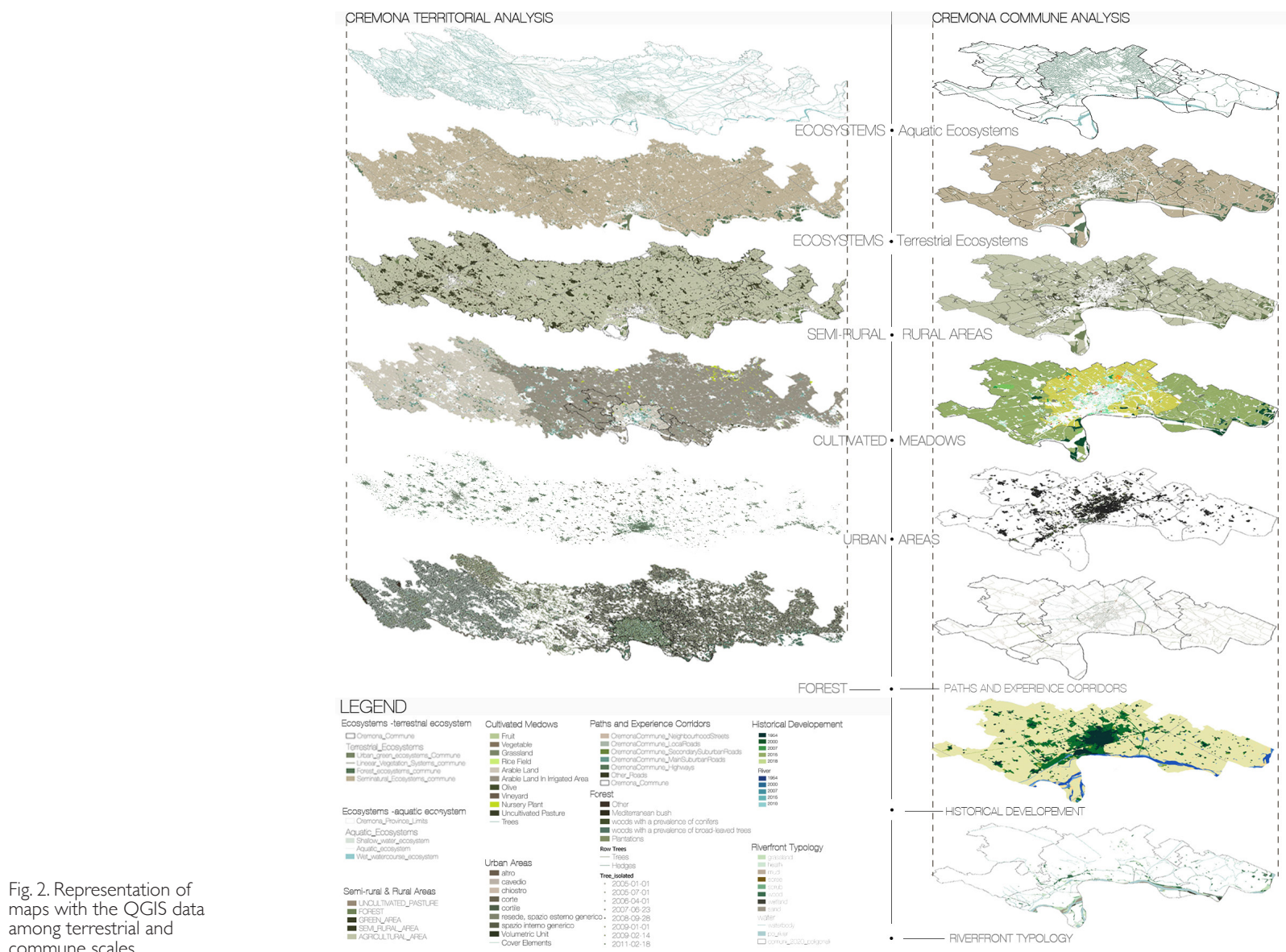

However, in order to come to a final understanding of these landscape elements, a synchronic analysis was also done by overlaying the historical maps of Cremona (fig. 3). Following this way, we highlighted the evolution of the city growing and the relative erosion of the surrounding landscape, with particular attention dedicated at the green pillow between city and river.This new zoom, with all the previous analysis' and data representation techniques, highlighting all the problems related to this green pillow that lies between city and river, as industrialization, abandoned sites, pollution. By the result of QGIS data we went ahead to decide the strategies for developing of the possible design connections in terms of slow mobility. 
Fig. 3. Synchronic analysis for the road matrix and semi natural/natural are distribution.

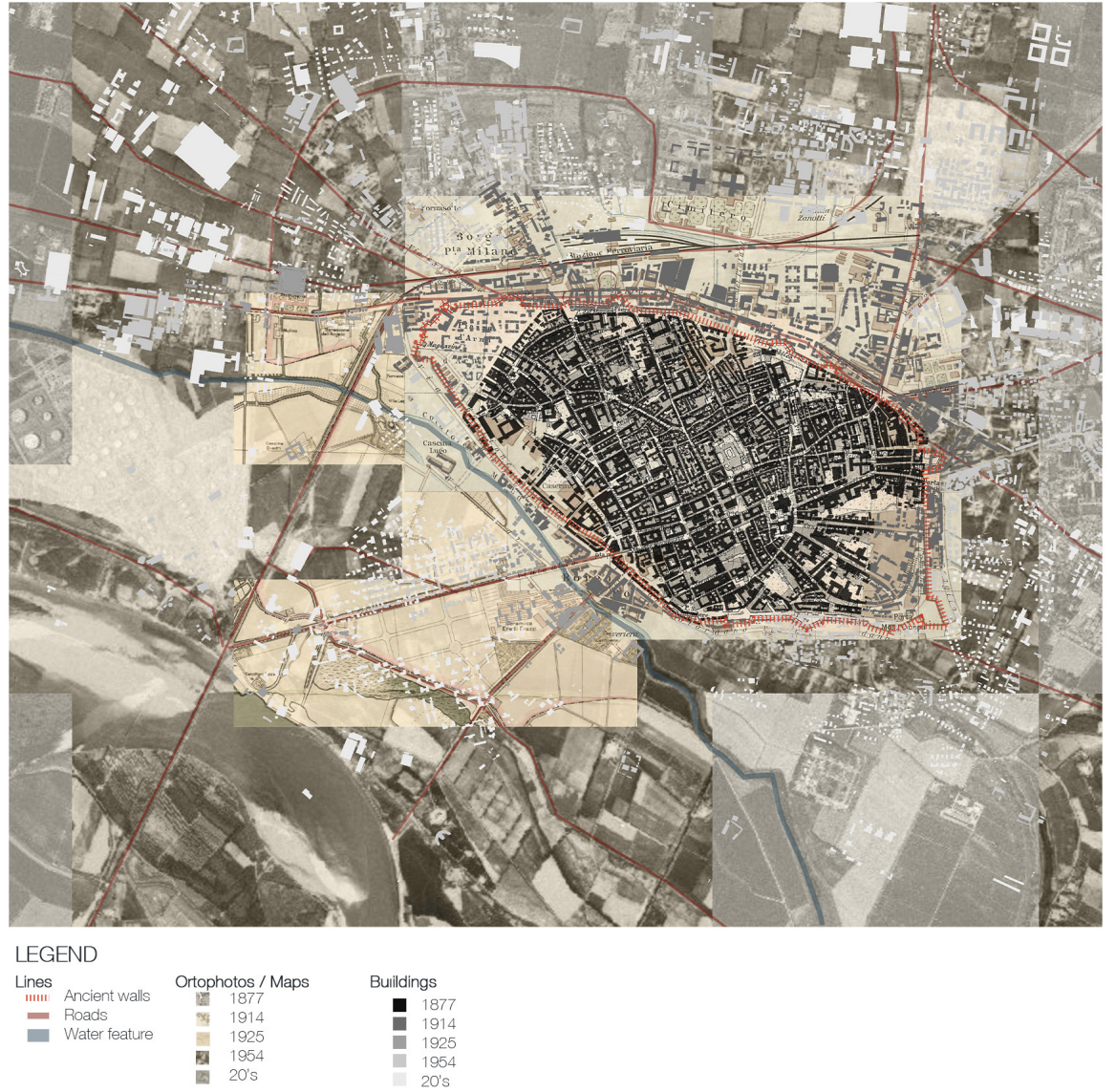

Within the related analysis points, the next step has been to understand the relationship between city and river, connection that represents the highest potential of landscape developing for the municipality of Cremona, and for all economy of the territory. In order to understand the character of this area and the relative quantitative and qualitative features of the soils, QGIS analysis was needed because the available maps did not be enough detailed for our intentions of research.

The seasonal evolution of the greenery (fig. 5) was created by using the formula for "Normalized Difference Vegetation Index NDVI" for three different seasons of 20 I9, and it has been calculated to understand how should be approached to the area while regenerating the greenery, for instance for the interpretation of the plant health.

$\mathrm{NDVI}=(\mathrm{NIR}-\mathrm{RED}) /(\mathrm{NIR}+\mathrm{RED})$

The formula combines the information available in the red and NIR bands into a single and representative value. Conducting NDVI analysis can lead where to investigate further or do broader damage assessment, if you already know which factors are influencing plant health. Values between - I and 0 indicate dead plants, or inorganic objects such as stones, roads, and houses. NDVI values for live plants range 0 to I, with I being the healthiest and 0 being the least healthy.

The intervals that can help to compare maps easily are:
- I to 0: Dead plant or object
0 to 0.33 : Unhealthy vegetation
0.33 to 0.66 : Moderately healthy plant
0.66 to I:Very healthy plant

So on, Annual Evolution of the soil was analysed by calculating 3 factors: the Normalized Difference Vegetation Index (NDVI), the Normalized Difference Tillage Index (NDTI) about the percentage of cultivated soil, and the Built Up Index (BUI) about the percentage of built soil, in three different years 2018,2019 and 2020, interpretating the evolution of each one. 


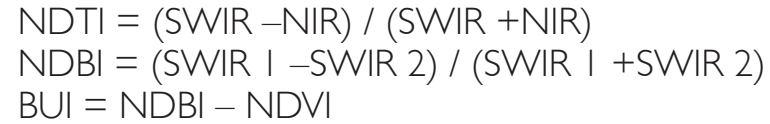

The thresholds that were considered to compare maps include some information like for instance very healthy vegetation for NDVI, built up and bare / cultivated soil for BUI and NDTI. In maps of NDTI, values between 0 to 0 . I shows built up area, and values between 0.1 and 0.2 show bare soil. In maps of BUI, values between 0 to 0.05 shows both built up area and bare soil, which are not separable.

As a green integration (fig. 6), all the missing green areas were found which are not included in Cremona urban green areas, such as private courtyards and gardens, in order to complete the green plan of the area municipality. For this purpose, we calculated NDVI as equation: $\mathrm{NDVI}=(\mathrm{NIR}-\mathrm{RED}) /(\mathrm{NIR}+\mathrm{RED})$

After that, a raster file with NDVI $>0.2$ was made which helps to find all sparse vegetation such as shrubs, grasslands, and senescing crops. To carry out this action, utilizing a false-color map and google satellite image are utilized. Using the near-infrared, red, and green spectral bands mapped to RGB - this image shows vegetation in a red tone, as vegetation reflects lightest in the near-infrared and we took advantage of this feature to find missing or incomplete greeneries.

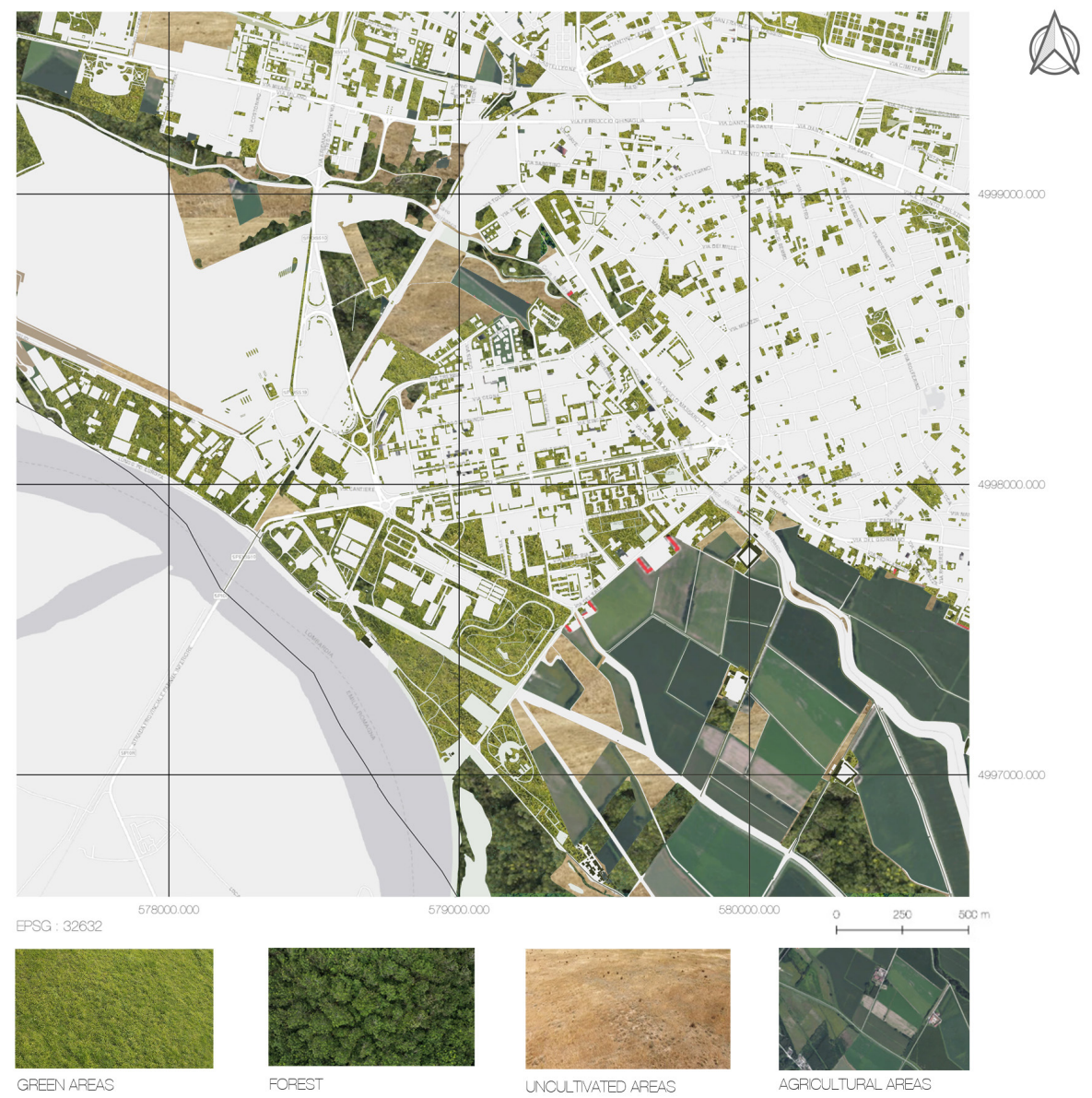

False-color image: R: NIR band G: Red band B: Green band For the next step, a new layer was created for digitizing on-screen some green areas or even improve some existing ones is needed in the fig. 6. In light of the QGIS data, texture and historical reading, a classification of the green characters of the related green belt is defined as a initial study field for the following designing strategies. 

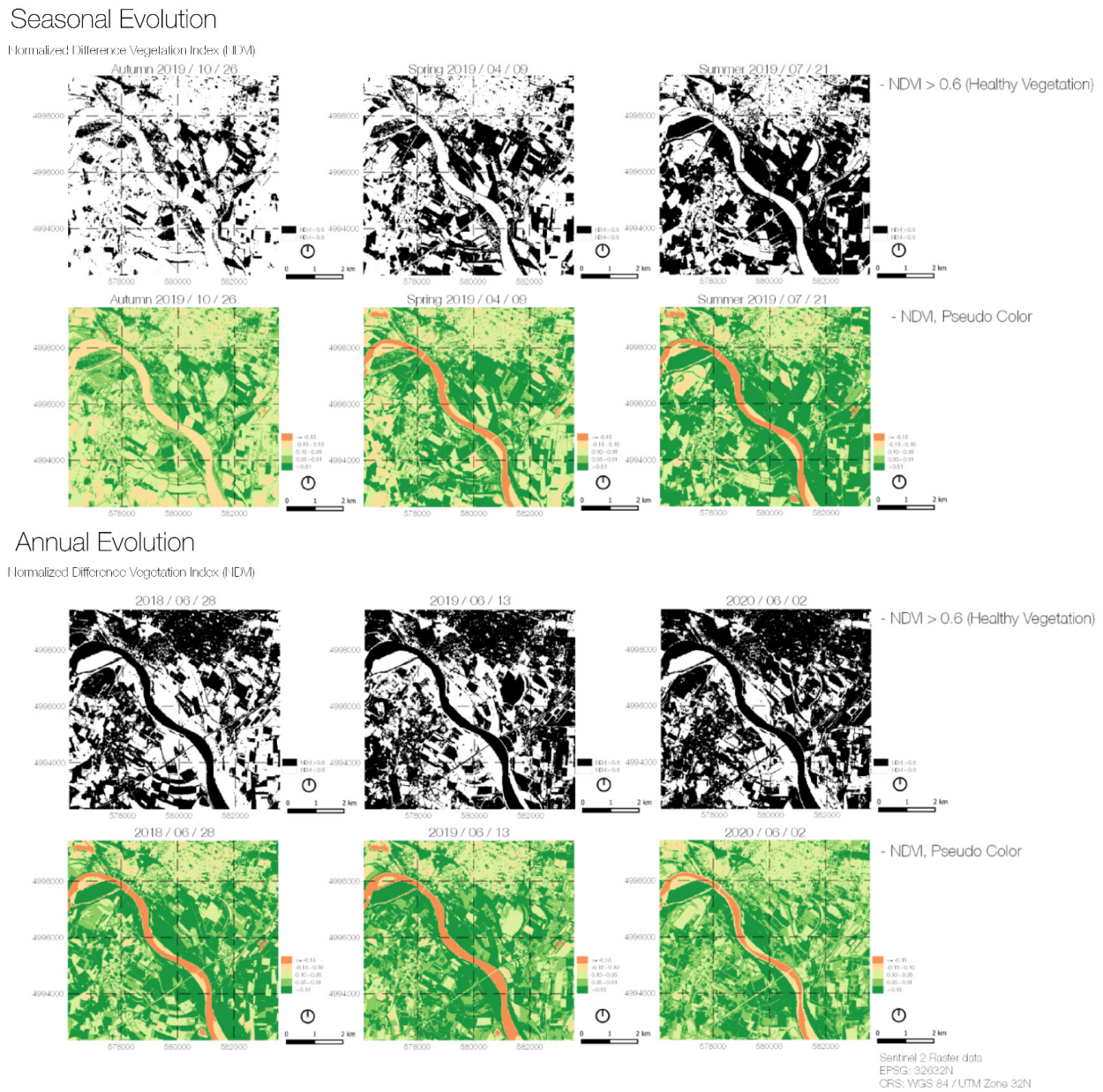

The urban green characters land cover is always limited. There are instances of green bleeding in the city with the elements of watercourse and natural greens exists yet mostly the green is limited, surrounded by built environment. The soil is completely covered with human interventions with the exception of urban parks with the typology of enclosed definitions. Furthermore, we analyzed also the riparian greenery as interface between landscape and the river, where this buffer zone between wet ecosystems and terrestrial ecosystems lies. The green area charactering this land works like a buffer between river and the banks, and it is occulated by hydrophilic plants. The natural green character, less contaminated, is mainly concentrated in these areas, with the Parco del Morbasco and Parco del Po.They are natural parks -as far as possible- that still connects existing and contiguous green areas. These areas still have characteristics of 'the big green belt', with an extensive forestation, unpaved and non-processed soils, also because they are under protection by national laws. Instead, the industrial area where there is an abandoned old refinery, is a place of high contamination. The zone is a big loss of the green belt that we have just described, with full paved soil coverage and high percentages of soil contamination, and we can imagine it as a 'potential greenery' area after a total conversion, reconnecting it to the natural parks.

We could say, at the end of this QGIS analysis, that this green belt is a as semi natural area, a sort of grey zone where the definitions differ among the classified landscape. In the landscape territory of Cremona, specially between city and Po river, we have a sort of contamination of human being activities with natural elements, and in many cases all the present greenery derives from a repetitive action of men on the soil. It does not exist a wild vegetation, an original one, but only a manipulated vegetation for productive reasons [Sereni 196I]. 
Fig. 6. Annual evolution of NDTI and BUI. Green integration.

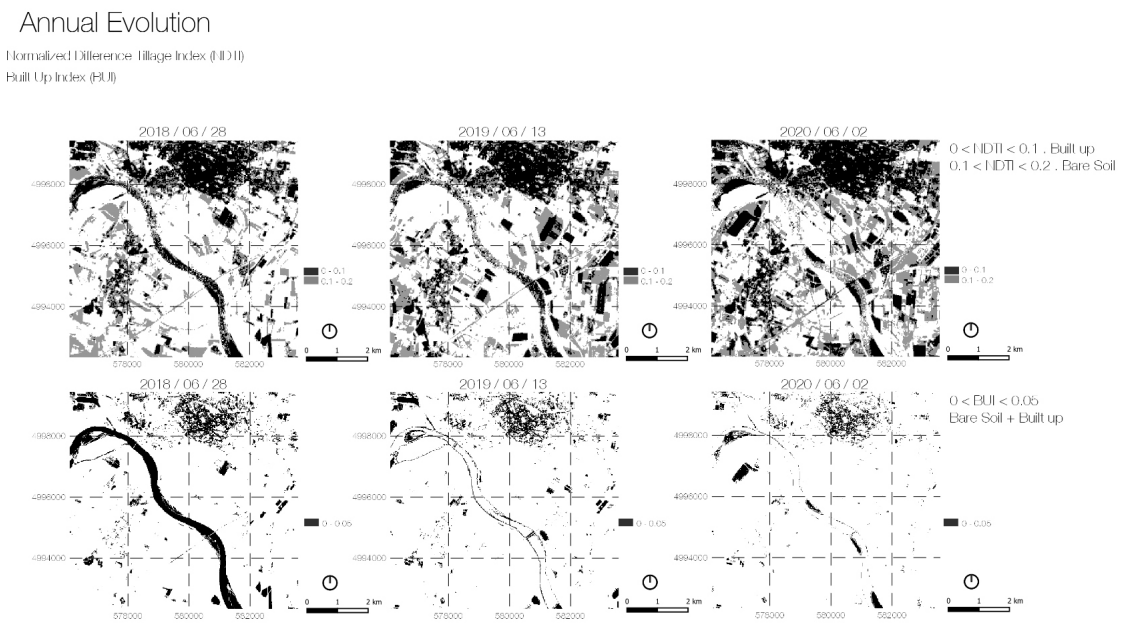

Urban Green Integration

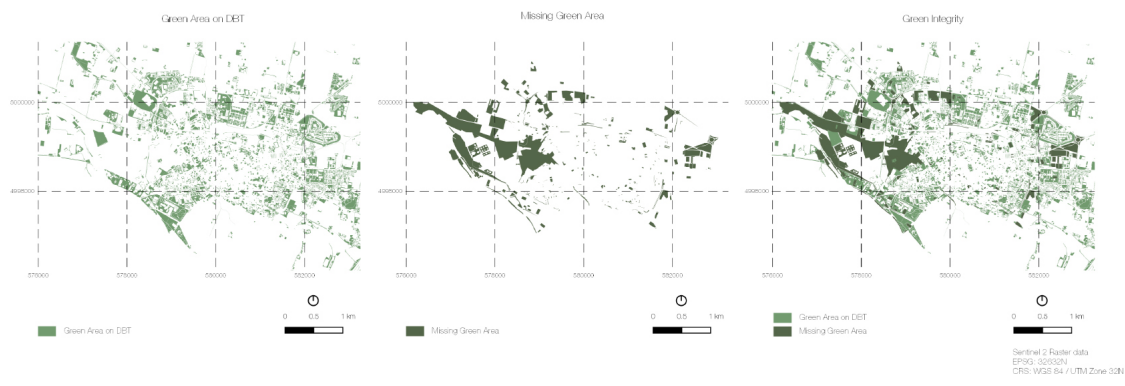

\section{Definition of the mobility connections}

The aim of the research is to study a possible integrated path that connect the city and the river [Secchi 2003]. Therefore, the green belt being the element of connection, it is important to experience all green elements along the path. However, within this path, there are zones needs landscape rescue in order to be correctly defined as a qualitative green. The boundaries of the path and area were determined for the green loop that were aimed to identify the distribution of the existing green areas, land use, density and the use of different typologies with the connections. So, we have identified five nodes of the ring, and the goal has been to connect these different places and form a loop focusing on the components of the city towards the riverside and characterized areas around the river that fragmented over time.

By photorealistic sections, we studied the resources in the area, discovering continuity or disconnections of them, physical and experiential understanding of the zones analyzed. Likewise, also being able to materialize the experience with these long sections looking at the internal landscape far from the path (fig. 7), it was possible to understand the relationship between built environment, greenery, people, scale and vehicles, and where landscape needs attention to be implemented with functional elements or new vegetation. In fact, as it was represented in the bigger scale analysis, it is important to see the texture of the landscape in order to define characteristics. By creating an open string section technique, the specific zones were discovered and analyzed by means of color, theme, movement, experience and scale of representation, determining the relationship between different ecosystems, ecotone areas, and buffers with different combinations, that until now, did not be studied and connected. 


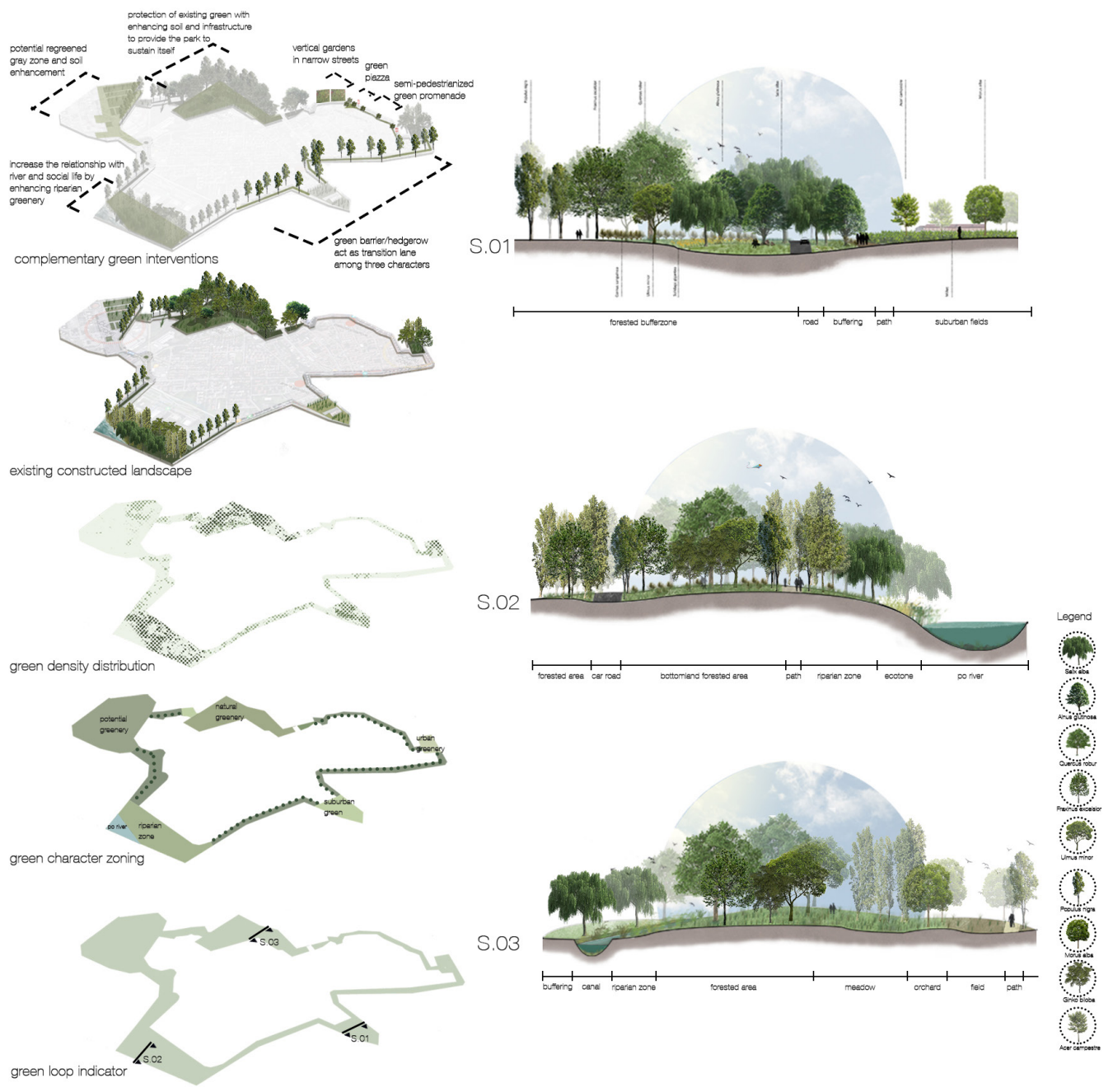

By applying specified characters to the specific experience points, it was discovered that there are some nodes of missing links of experience. Such as the urban area, which is a very strong experiential path, which will not allow any green bleeding, but is also cut with a strong end in the beginning of natural areas. These abstract representations created the awareness of creating connection strategies also among experiential using of the landscape.

\section{Strategies of landscape rescue}

Under the light of all representation and analysis both of the scientific and social perspectives, it was necessary to find points of strategies defined by intersections of the needs among the green loops. The main discovery has been discontinuity among the experiences hence the green belt, so the design strategy was to recreate the landscape character of the green belt [Brick, Lewis 2016], which in many points lacks the sense among activities, greenery and facilities [Corboz 1983]. While approaching the landscape, paths was reconsidered according to the history of the places, and in terms of remediation matter treating soil, water and the vegetation. The quality and the character of the greenery is analyzed one more time in the third dimension with sections (fig. 8).

Different approaches were made for each of them, regarding the green character defined before and solutions were offered. Firstly, the soil must be rescued with the water quality in 
mind since these areas has relatively higher physical relationships with the water. It is aimed that the soil to be cleaned by phytoremediation [Sleegers 20 I0]. by planting of some new yet familiar vegetation. Then, in the agricultural fields, cleaning the quality of the crops can be improved by the support to the soil. Adding trees for phytoremediation, to increase the biodiversity from the bigger animals, all the way to the bugs to help pollination. Lastly, the urban soil is need of rescue, hence the amount of built environment. Recommended porous pavement significantly decreases the risk of storm water runoff and erosion by allowing the soil to be permeated by water. These are only few instances for a possible strategy of landscape managing.

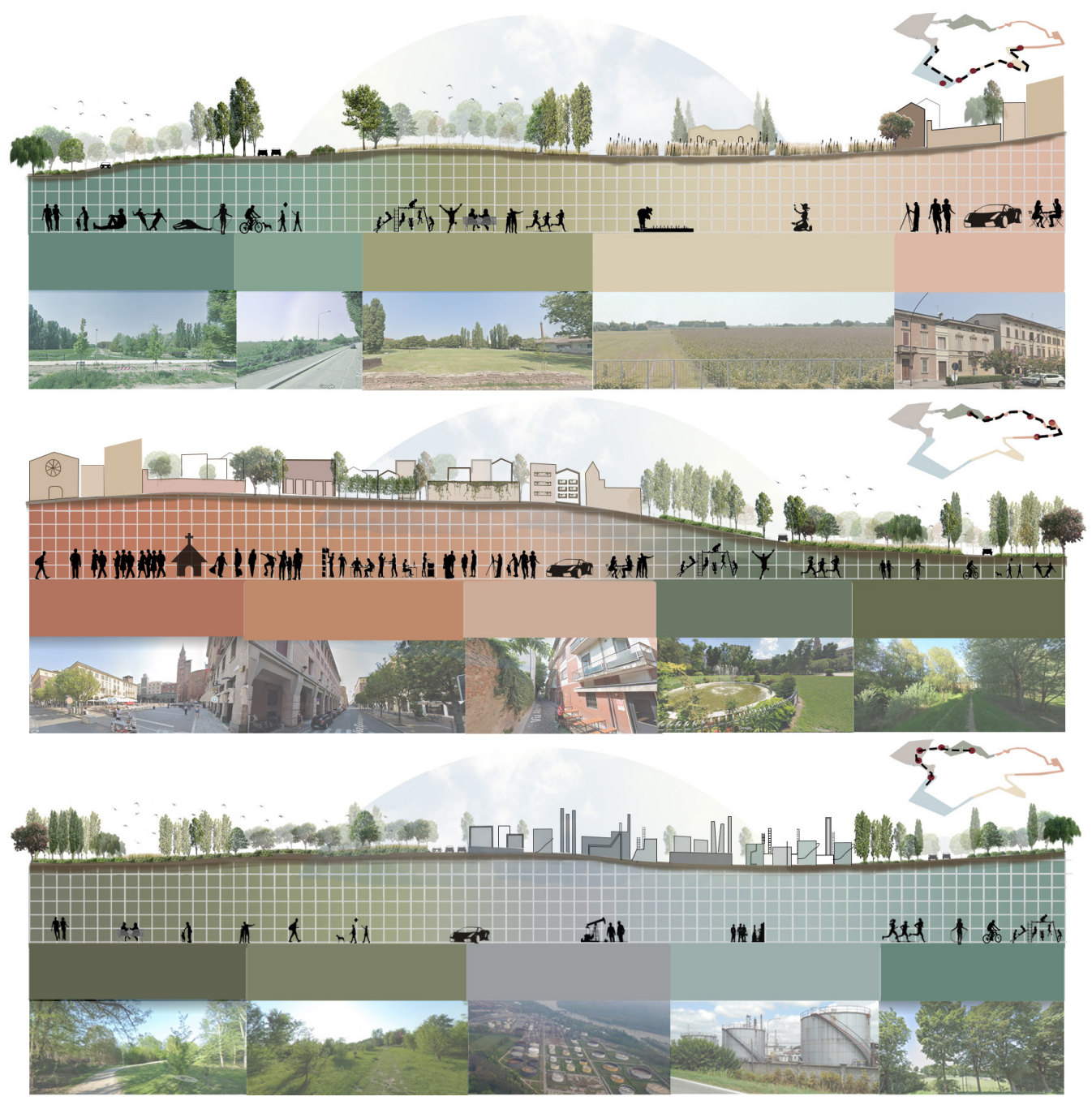

\section{Conclusions}

As a result of this research, ecosystematic land cover, green characters among the green belt, which discovered as the main connection for the city and the river, users and soil typologies were analyzed and represented. In terms of sustaining the territory and environmental quality, the existing green areas were enhanced by necessary environmental strategies and increase in the mass ratio of green is provided to regain the definition of the green belt in the area.The path, which mainly aims the human experience to understand all the character of the greenery, has been left natural and improved infrastructural aspects and at some points rescued as a landscape. Within these strategies, the area will be an inviting industrial 
green park and the big gap on the green belt will be fulfilled with green elements with the green loop path. It is considered appropriate to develop these slow mobility strategies also in the present Covid-19 pandemic situation, in an attempt to minimize the spreading of virus infection. In this perspective, it is important to encourage forms of active and proximity mobility [Bianchi, D'Uva et. al. 2020], also to develop an approach that allows us to rediscover in a sustainable way the areas less frequented by the mass tourism, at the same time taking into careful account their internal fragility. This design-oriented approach to territorial strategies will produce long term, durable benefits of which both the insiders (permanent inhabitants) and the outsiders (temporary inhabitants or tourists) will benefit.

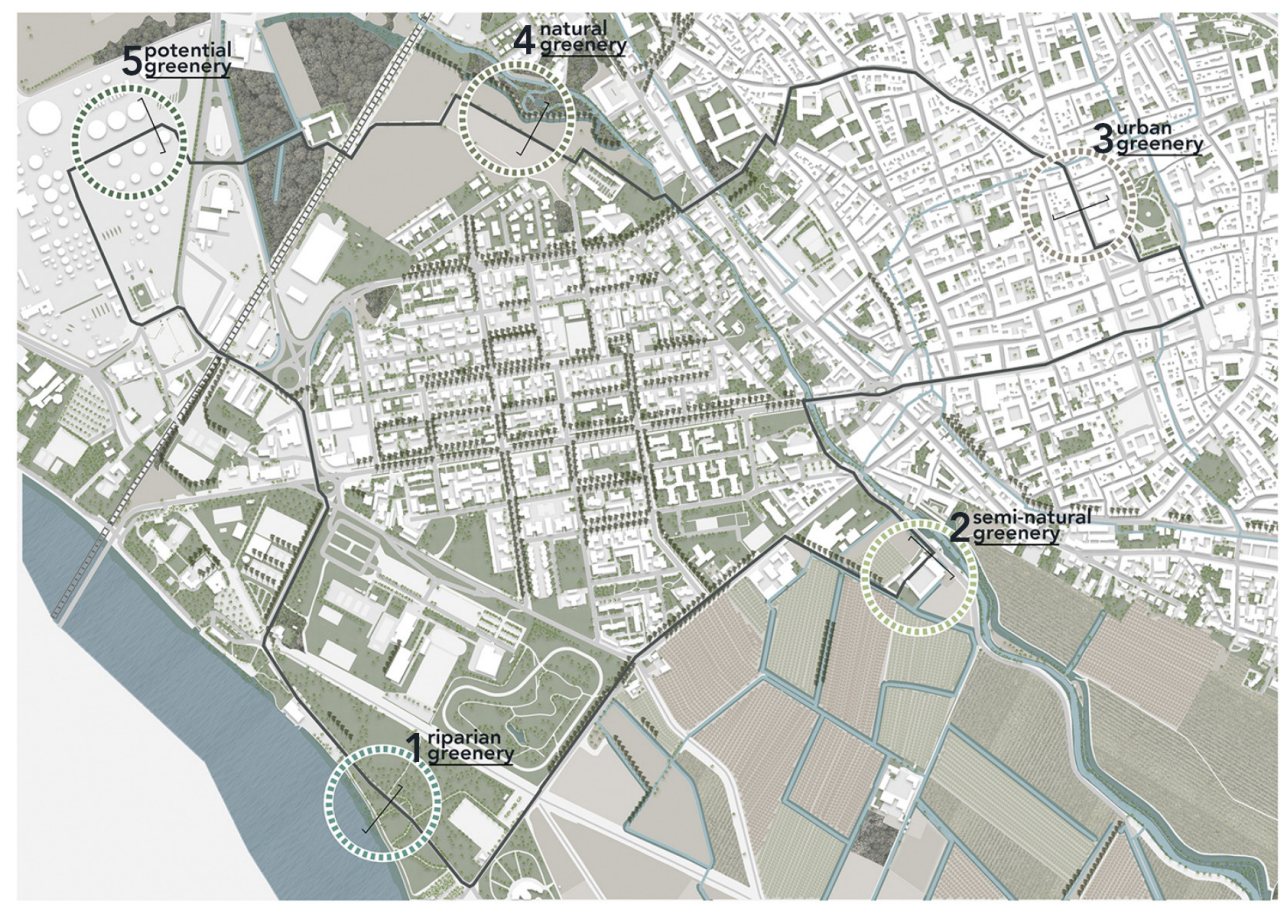

LEGEND

Natural Environment

Urban greenery

- Uncultivated pasture

- Agricultural field

-

inilina Alfalfa

iㅣㄹ

and Forest

6. isolated tree

iit Tree row

- Riverbed

Waterways

믈 River

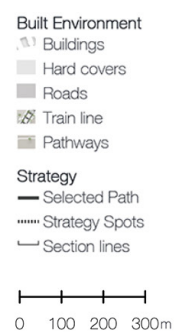

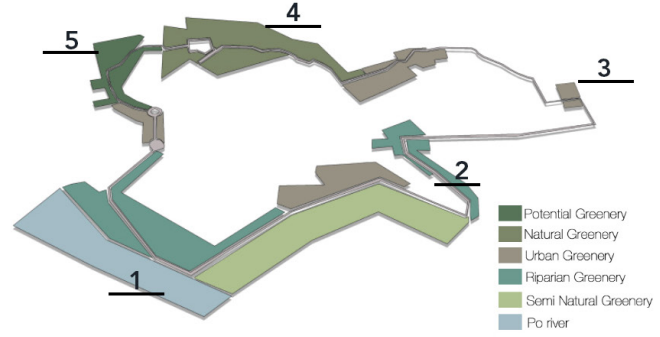

\section{Acknowledgments}

This work has been carried on within the activities of the Landscape Representation group of the Pole of Piacenza, Politecnico di Milano (Alessandro Bianchi, Giovanna Sona. Direction, Andrea Asti, Mattia Belloni, Alessia Damone, Gianmarco Paris - Assistants, E. Demre, K. Kardelen, K. Fatemeh, M. S. Mona, N. S. Dokht, O. A. Ahsen, S. Seyedehfatemeh, T. Sezin, U. Seray) and the research included in the Fragile Territories developed by the Department of Architecture and Urban Studies.

\section{References}

Bianchi A. et al. (2020). A View from the Track: measuring spatial quality of slow mobility routes. Possible integration of GIS and machine learning based methods. In A. Arena et al. (a cura di). Connettere. Un disegno per annodare e tessere. Atti del $42^{\circ}$ Convegno Internazionale dei Docenti delle Discipline della Rappresentazione/Connecting. Drawing for weaving relationships. Proceedings of the 42th International Conference of Representation Disciplines Teachers, pp. 2973-2980. Milano: FrancoAngeli. 
Bianchi A., D'Uva D., Rolando A. (2020). An innovational digital tool in gis procedure: mapping Adriatic coast in Abruzzo region to support design of slow mobility routes. In Int. Arch. Photogramm. Remote Sens. Spatial Inf. Sci., XLIII-B4-2020, pp. 533-537.

Brick C., Lewis G. (2016). Unearthing the "Green" Personality: Core Traits Predict Environmentally Friendly Behavior. Environment and Behavior. In Environment and Behavior 2016, vol. 48(5), pp. 635-658

Clément G. (2004). Manifeste du Tiers paysage. Paris: Éditions Sujet/Objet.

Congedo L. (202I). Semi-Automatic Classification Plugin Documentation. Available at: <https://semiautomaticclassificationmanual. readthedocs.io/en/latest/> (accessed 202I, November II).

Corboz A. (1983). The land as Palimpsest. In Diogenes, vol. 31 , issue I 21, pp. I2-34.

Lee S.W. et al. (2009). Landscape Ecological Approach to the Relationships of Land Use Patterns in Watersheds to Water Quality Characteristics. In Landscape and Urban Planning, 92. pp. 80-89.

Liu M., Nijhuis S. (2020). Digital Methods for Mapping Landscape Spaces in Landscape Design. In Journal of Digital Landscape Architecture, 5, pp. 634-645

Regione Lombardia: <http://www.geoportale.regione.lombardia.it/en/home> (accessed 202I, November II).

Secchi B. (2003). Projects, visions, scenarios. In Planum. The Journal of Urbanism, n. 7, vol. 2. Available at http://www.planum.net/ three-stories-for-the-xxth-century (accessed 2016 October 12).

Sereni E. (196I). Storia del paesaggio agrario italiano. Bari: Laterza.

Sleegers F. (2010). Phytoremediation as Green Infrastructure and a Landscape of Experiences. In Proceedings of the Annual International Conference on Soils, Sediments, Water and Energy, vol. I5, article I3, pp. I 32-I40.

State Archives of Cremona, Cadastral Maps of 1877, 1914, 1925, 1954: <http://www.archiviodistatocremona.beniculturali.it/ catasto-teresiano/cremona> (accessed 2021, November II).

\section{Author}

Alessandro Bianchi, Politecnico di Milano, alessandro.bianchi@polimi.it

To cite this chapter. Bianchi Alessandro (2021). Ecosystems and green connections: representation and strategy for Cremona landscape. In Arena A., Arena M., Mediati D., Raffa P. (a cura di). Connettere. Un disegno per annodare e tessere. Linguaggi Distanze Tecnologie. Atti del $42^{\circ}$ Convegno Internazionale dei Docenti delle Discipline della Rappresentazione/Connecting. Drawing for weaving relationship. Languages Distances Technologies. Proceedings of the $42^{\text {th }}$ International Conference of Representation Disciplines Teachers. Milano: FrancoAngeli, pp. $1370-1380$. 